\title{
Diagonal compression testing of masonry panels with irregular texture strengthened with inorganic composites
}

\author{
Marta Del Zoppo (D) Marco Di Ludovico - Alberto Balsamo - Andrea Prota
}

Received: 6 March 2020/ Accepted: 23 July 2020 / Published online: 30 July 2020

(C) The Author(s) 2020

\begin{abstract}
Inorganic composites for enhancing the in-plane shear capacity of masonry walls with irregular texture were investigated on twenty-one panels under diagonal compression tests. Three specimens were used as control and twelve specimens were strengthened with two Fibre Reinforced Mortars (FRM-A and FRM-B), characterized by a different content of fibres embedded in the lime-based matrix. The remaining six specimens were strengthened with Fabric Reinforced Cementitious Mortars (FRCM), consisting in a GFRP grid embedded in a fibre reinforced matrix (the same used for FRM-A). The influence of single-side and double-side strengthening configurations on the capacity of strengthened panels was also investigated, to point out the reduction in strengthening effectiveness in case of single-sided applications. The results showed that all the inorganic composites adopted for the strengthening techniques provided a substantial increase of shear capacity. The grid in FRCM strengthened panels played an important role in both strength and deformation capacity at peak. The different fibres content (lower than 50\% in weight) in FRM systems slightly affected the overall performance of panels. Finally, analytical predictions
\end{abstract}

M. Del Zoppo $(\bowtie) \cdot$ M. Di Ludovico · A. Balsamo ·

A. Prota

Department of Structures for Engineering and

Architecture, University of Naples Federico II, Naples,

Italy

e-mail: marta.delzoppo@unina.it of experimental results were reported and discussed and a preliminary analytical model for estimating the FRM shear contribution was proposed, obtaining a good agreement with test results.

Keywords FRCM · FRM - TRM - Masonry with irregular texture $\cdot$ In-plane shear strengthening

\section{Introduction}

Existing masonry buildings in seismic areas are particularly vulnerable to heavy damage due to the reduced in-plane shear capacity of piers [1]. This problem is even more evident in the case of poor quality masonry walls with a lack of transverse connections or with an irregular texture (i.e. uncoursed) [2]. Indeed, it is recognized that the mechanical behaviour of masonry walls with irregular texture is generally poor as shear cracking may easily occur only in the mortar joints, not involving the stone blocks [3].

Recently, the use of inorganic composites has been largely investigated for improving the in-plane shear capacity of masonry panels, due to their higher compatibility with the masonry substrate and their suitability with a life-cycle design of retrofit interventions. Among the inorganic composite materials, three main classes can be identified: Fibre/Fabric 
Reinforced Cementitious Mortar (FRCM, also known as Textile Reinforced Mortar or TRM), Composite Reinforced Mortar (CRM) [4], and Fibre Reinforced Mortar (FRM) [5]. FRCM and CRM systems both consist in an FRP grid (or mesh reinforcement) embedded in the inorganic matrix. CRMs are characterized by the use of FRP grids with a yarn spacing higher than $30 \mathrm{~mm}$ and by a thickness of the matrix layer usually greater than $30 \mathrm{~mm}$, that is much larger than that commonly adopted for FRCM systems (ranging between 6 and $10 \mathrm{~mm}$ ) [6-8]. Furthermore, in the case of CRM the FRP yarns are pre-impregnated with epoxy resin to form a laminated or pultruded grid, resulting in a higher stiffness with respect to textile adopted for FRCM [7]. Conversely, the FRM system consists in a fibre reinforced matrix layer without any mesh or textile reinforcement. All these inorganic composite materials are characterized by the use of inorganic matrices, consisting of cement or lime-based mortars. The behaviour of masonry panels strengthened with FRCM and CRM systems has been widely investigated so far. A number of 414 diagonal compression tests are currently available in literature for such strengthening solutions and they have been collected in [9]. This study pointed out that a large number of tests has been carried out on masonry panels with a regular texture (i.e. solid/hollow clay brick, regular tuff blocks, concrete blocks). Conversely, only few experimental programs investigated the effectiveness of such strengthening solutions for masonry panels with irregular texture [10-13]. Furthermore, the use of FRM systems for the in-plane shear strengthening of masonry walls was less investigated than other inorganic composites. A few applications can be found in literature only for clay brick masonry wallets strengthened with fibre reinforced plasters [5, 14]. Some tests on solid clay brick masonry walls strengthened with only mortar without microfibers were also performed [15-17]. To the knowledge of the authors, tests on masonry brickworks with irregular texture strengthened with FRM systems have never been performed before.

The use of two classes of inorganic composites, FRCM and FRM, was herein investigated for improving the in-plane shear capacity of limestone masonry panels with irregular texture, typical of the Central Italy regions. The experimental program consisted of 21 panels tested under diagonal compression. Three unreinforced masonry panels (URM) were used as control and twelve specimens were strengthened with two types of Fibre Reinforced Mortars (FRM-type A and FRM-type B), characterized by the same type of glass fibres with different fibre content ratios. The other six specimens were strengthened with Fabric Reinforced Cement Mortars (FRCM), consisting in a GFRP grid embedded in a fibre reinforced mortar. The fibre reinforced mortar used as matrix for the FRCM systems was the same of FRM-A, in order to point out the role of the grid in resisting mechanism. All strengthening techniques were tested in both singleside and double-side configurations. The experimental results were analysed, to understand the incidence of the grid of the fibre content on the resisting mechanism of panels strengthened with inorganic composites. The performance of limestone masonry panels with irregular texture was also compared with that of clay brick panels strengthened with same technique [5], to investigate the effect of the quality of masonry on the effectiveness of the strengthening solution. Finally, the analytical models provided by CNR-DT 215 [18] and ACI 549.4-R13 [19] were adopted for predicting the shear contribution of FRCM systems, and a preliminary analytical model has been proposed for estimating the shear contribution of FRM systems. Mean amplification factors for the peak shear strength were also derived from experimental tests for each strengthening technique (FRCM, FRM) and reinforcement configuration (single-side, double-side).

\section{Experimental programme}

\subsection{Mechanical characterization of materials}

The masonry panels were made of irregular medium sized blocks of limestone, typical of Central Italy regions. A premixed hydraulic mortar composed by natural hydraulic lime with 1:5 water/powder ratio by weight (i.e. $5 \mathrm{~L}$ of water per $25 \mathrm{~kg}$ of sand) and pozzolanic additives has been used for bed joints. The mortar composition was designed in a way to reproduce the main features of old mortar types in historical masonry buildings. This premixed hydraulic mortar was classified as M5 by Eurocode 6 [20] and Italian Building Code [21].

Three inorganic composites were used as strengthening techniques: FRCM; FRM-type A (i.e. FRM-A) and FRM-type B (i.e. FRM-B). 
The FRCM system consisted of a glass grid $25 \mathrm{~mm} \times 25 \mathrm{~mm}$, characterized by an equivalent thickness of $0.035 \mathrm{~mm}$ (unit weight $225 \mathrm{~g} / \mathrm{m}^{2}$ ), embedded in an inorganic matrix. The mortar adopted as matrix was a lime-pozzolan based mortar made by hydraulic natural lime, sand, polymeric additives (lower than $10 \%$ in weight) and short glass fibres spread in the mix (12 mm length, fibre content $<1 \%$ in weight).

The FRM-type A system consisted in the use of a fibre reinforced mortar as strengthening solution, without any additional grid. The fibre reinforced mortar was the same used as matrix for the FRCM system.

The FRM-type B system consisted of a limepozzolan based mortar made by hydraulic natural lime, sand, polymeric additives (lower than 10\% in weight) and fibres spread in the mix (fibre content $<1 \%$ in weight). Mortars used for FRM-A and FRM-B differed only for the fibre content. Indeed, FRM-B had a higher fibre content, and the difference in fibre content between the two was less than $50 \%$ in weight.

The mechanical characterization of the materials adopted in this experimental programme was derived from experimental tests. For the mortars, compression tests on four $40 \times 40 \times 40 \mathrm{~mm}^{3}$ cubic specimens were carried out according to UNI EN 772 [22]. Three points bending tests were also performed on three specimens with dimensions $40 \times 40 \times 160 \mathrm{~mm}^{3}$, according to UNI EN 1015-11 [23], to evaluate the flexural strength. The tests were performed under displacement control (displacement rate $0.01 \mathrm{~mm} / \mathrm{s}$ ) after 28 days from the casting. The mean values of mortars were given in Table 1, along with the

Table 1 Materials mechanical properties: mean values (CoV)

\begin{tabular}{lll}
\hline Material & $\begin{array}{l}f_{c} \\
(\mathrm{MPa})\end{array}$ & $\begin{array}{l}f_{t} \\
(\mathrm{MPa})\end{array}$ \\
\hline Bed joints mortar & 5.5 & $0.9 *$ \\
& $(8.5 \%)$ & $(3.3 \%)$ \\
FRM-type A & 14.5 & $6.6^{*}$ \\
FRM-type B & $(8.8 \%)$ & $(1.1 \%)$ \\
& 13.61 & $6.0^{*}$ \\
& $(7.3 \%)$ & $(8.3 \%)$ \\
\hline
\end{tabular}

*From three points bending tests coefficient of variation $(\mathrm{CoV})$ related to mechanical properties experimentally derived by the authors. In particular, mean compressive strength, $f_{c}$, and flexural strength, $f_{t}$, were reported.

Mechanical properties of the GFRP grid were derived from tensile tests on four yarns performed according to EN ISO 10618/2005 [24]: tensile strength, $f_{f}=1010 \mathrm{MPa}(\mathrm{CoV}=7.6 \%)$, Young modulus, $E_{f}=70 \quad \mathrm{GPa} \quad(\mathrm{CoV}=1.2 \%)$ and $\varepsilon_{\mathrm{f}}=1.4 \%$ $(\mathrm{CoV}=9 \%)$. Special aluminium tabs were bonded at the ends of the coupons with epoxy resin, to avoid local failures close to the grips. The tabs' dimensions were equal to $100 \times 100 \times 2 \mathrm{~mm}^{3}$, whereas the dimensions of GFRP coupons were $100 \times 700 \mathrm{~mm}^{2}$.

\subsection{Specimens details and strengthening configurations}

The experimental in-plane shear capacity of 21 masonry panels, made of rubble limestone blocks arranged with an irregular texture, was experimentally evaluated by means of diagonal compression tests.

The panels had global dimensions $1200 \times 1200 \times 300 \mathrm{~mm}^{3}$, and were made of irregularly shaped limestone blocks with similar dimensions, randomly arranged in the wooden formwork as shown in Fig. 1a. Bed joints were made with the limebased mortar (Fig. 1b). Due to the manufacturing process, the panels were characterized by an irregular texture, typical of existing masonry buildings in Central Italy regions (Fig. 1c). The specimens were built and cured as per site conditions and were strengthened after their curing period.

Three unreinforced masonry (URM) panels were tested as control. The other specimens were strengthened with inorganic composites, as summarized in Table 2, with three strengthening techniques (FRCM, FRM-A and FRM-B). For each technique, both the double-side strengthening configuration and the single-side one were tested. Three specimens were tested for each strengthening technique and configuration, for a total of 18 strengthened panels.

The strengthening procedure for the FRCM technique consisted of: masonry pre-wetting; first coating of mortar with average thickness $10 \mathrm{~mm}$; application of the grid by hand-pressing; second coating of mortar with average thickness $5 \mathrm{~mm}$. The phases were also shown in Fig. 2. 


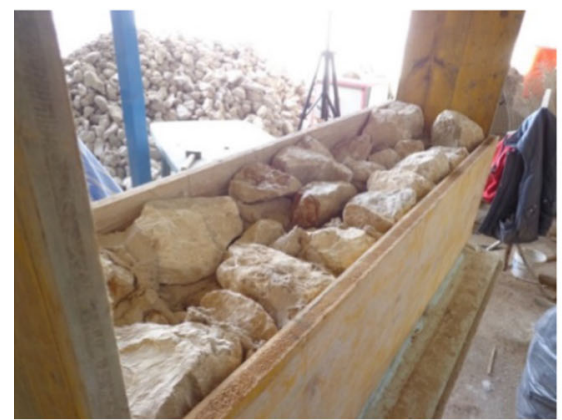

(a)

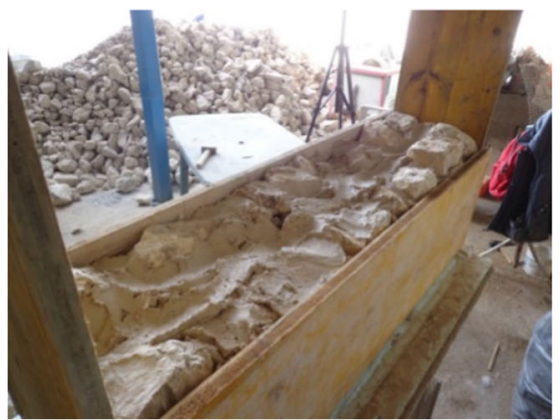

(b)

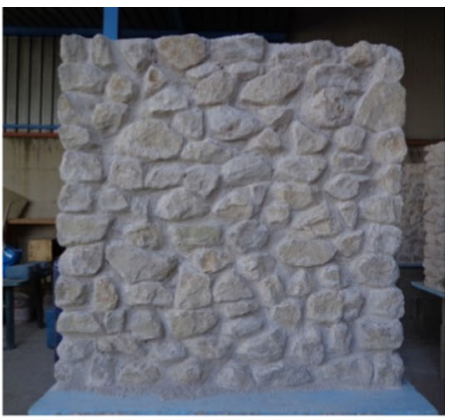

(c)

Fig. 1 Specimens manufacturing process: a layer of limestone blocks, b bed-joint mortar, c masonry panel after curing

Table 2 Summary of the experimental program

\begin{tabular}{|c|c|c|c|}
\hline Configuration & Strengthening system & Label & Grid \\
\hline \multirow[t]{3}{*}{ Control } & \multirow[t]{3}{*}{-} & C_a & - \\
\hline & & C_b & - \\
\hline & & C_c & - \\
\hline \multirow[t]{9}{*}{ Double side strengthening } & \multirow[t]{3}{*}{ FRCM } & 2FRCM_a & GFRP \\
\hline & & 2FRCM_b & GFRP \\
\hline & & 2FRCM_c & GFRP \\
\hline & \multirow[t]{3}{*}{ FRM-A } & 2FRM-A_a & - \\
\hline & & 2FRM-A_b & - \\
\hline & & 2FRM-A_c & - \\
\hline & \multirow[t]{3}{*}{ FRM-B } & 2FRM-B_a & - \\
\hline & & 2FRM-B_b & - \\
\hline & & 2FRM-B_c & - \\
\hline \multirow[t]{9}{*}{ Single side strengthening } & \multirow[t]{3}{*}{ FRCM } & 1FRCM_a & GFRP \\
\hline & & 1FRCM_b & GFRP \\
\hline & & 1FRCM_c & GFRP \\
\hline & \multirow[t]{3}{*}{ FRM-A } & 1FRM-A_a & - \\
\hline & & 1FRM-A_b & - \\
\hline & & 1FRM-A_c & - \\
\hline & \multirow[t]{3}{*}{ FRM-B } & 1FRM-B_a & - \\
\hline & & 1FRM-B_b & - \\
\hline & & 1FRM-B_c & - \\
\hline
\end{tabular}

In the case of FRM application, a single layer of mortar of thickness $15 \mathrm{~mm}$ was applied on the masonry surface, after the pre-wetting. In all strengthening configuration, the average thickness of the strengthening system was $15 \mathrm{~mm}$ and no mechanical anchors were adopted.

\subsection{Setup and instrumentation}

An ad-hoc designed set-up for off-site tests was used to perform diagonal compression tests (see Fig. 3). The specimens were tested under displacement control to allow monitoring of the post peak response with displacement rate $0.02 \mathrm{~mm} / \mathrm{s}$. Four linear variable displacement transducers (LVDT), two per each side of the panels, were installed along the two diagonals to 

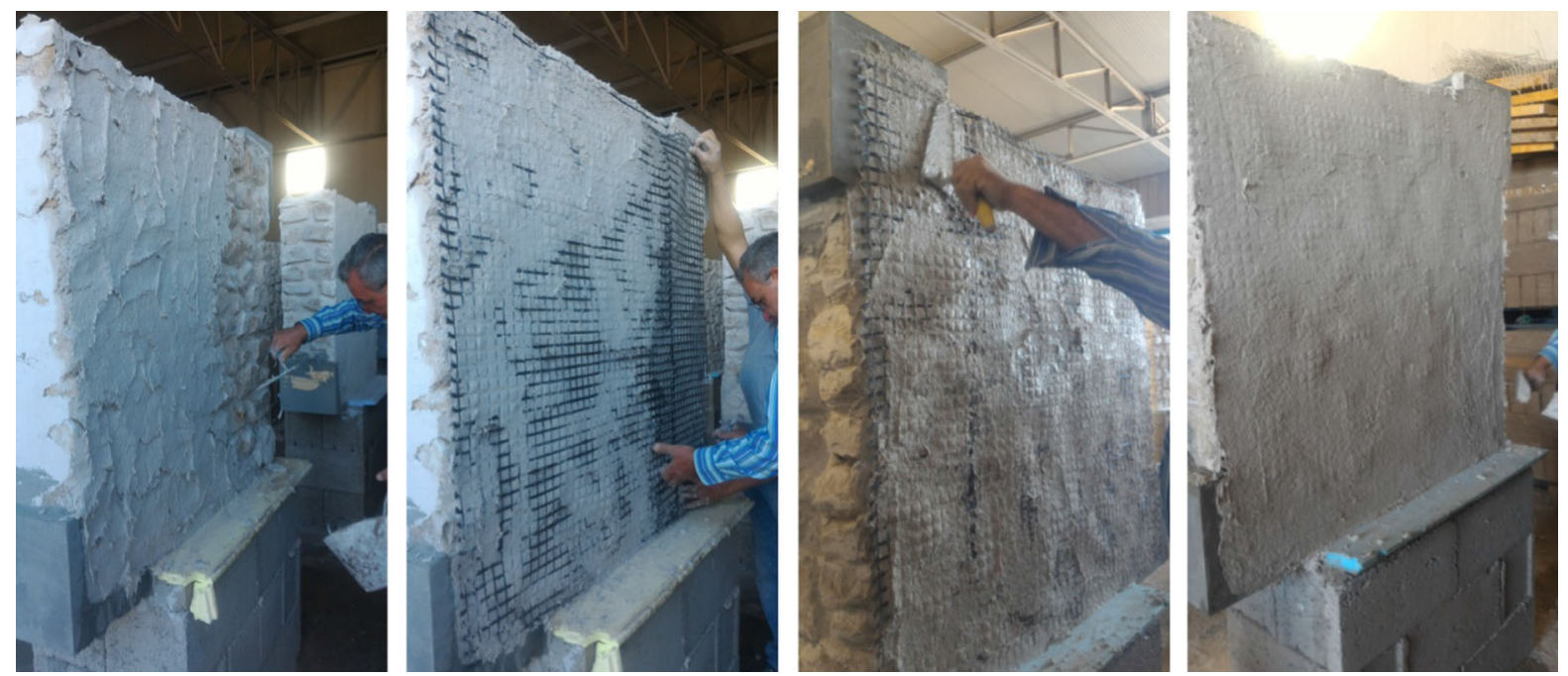

Fig. 2 Strengthening procedure for FRCM technique

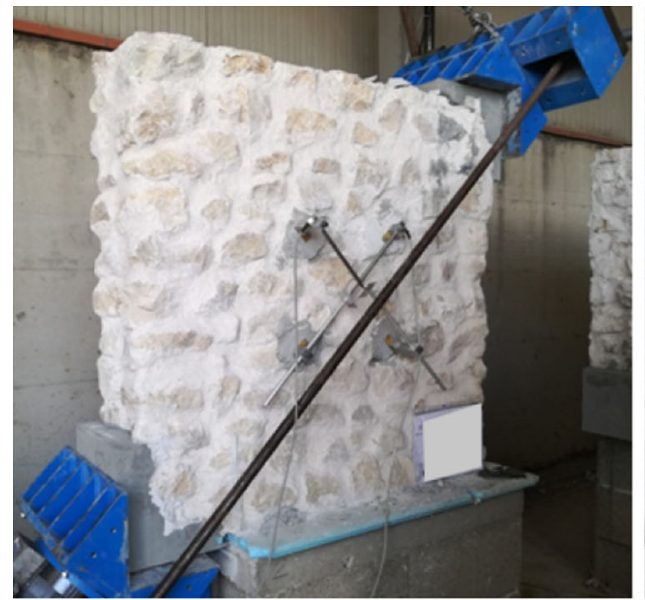

(a)

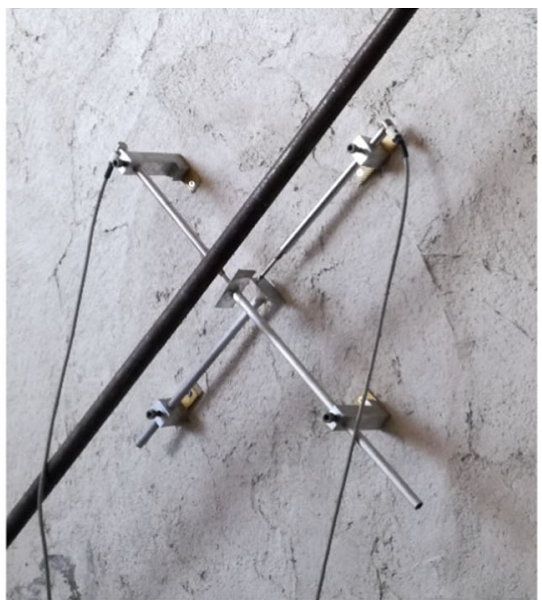

(b)

Fig. 3 Test setup for off-site diagonal compression tests (a) and LVDTs (b)

monitor the in-plane displacements along principal directions over a gauge length of $400 \mathrm{~mm}$. More details about the test set-up and the instrumentation can be found in Del Zoppo et al. [4].

\section{Experimental results}

The experimental outcomes were discussed in the following sections in terms of observed failure mode and stress-strain relationship for the specimens strengthened with FRCM, FRM-A and FRM-B techniques, respectively.

The experimental shear stress, $\tau$, was computed according to ASTM E 519-07 [25] previsions for diagonal compressive test, as reported in Eq. 1.

$\tau_{\mathrm{ASTM}}=\frac{0.707 P}{A_{n}}$ 
where $P$ is the applied load and $A_{n}$ is the net area of the specimen, calculated as $A_{n}=0.5(w+h) t$ with $w$ the panel width, $h$ the panel height and $t$ the panel thickness of the specimen.

The experimental shear strain, $\gamma$, was derived from the LVDTs records along the two diagonals of the specimen. The single LVDT record divided for its gauge length provides the longitudinal strain along the horizontal or vertical diagonals, $\varepsilon_{H}$ or $\varepsilon_{V}$ respectively. The average shear strain was then computed as the sum of the average horizontal and vertical strains recorded along the two diagonals, as reported in Eq. 2.

$\gamma=\varepsilon_{H, \text { average }+} \varepsilon_{V, \text { average }}$

The diagonal compression deformability factor, $\mu$, was evaluated as the ratio between average shear strain at failure, $\gamma_{u}$, and that at peak force, $\gamma_{\tau \max }$; the hear strain at failure was assumed as a strength degradation

Table 3 Experimental outcomes

\begin{tabular}{lllllr}
\hline Specimen & $\begin{array}{l}P_{\tau \max } \\
(\mathrm{kN})\end{array}$ & $\begin{array}{l}\tau_{\text {ASTM,max }} \\
(\mathrm{MPa})\end{array}$ & $\begin{array}{l}\gamma_{\tau \max } \\
(-)\end{array}$ & $\begin{array}{l}\gamma_{u} \\
(-)\end{array}$ & \multicolumn{1}{c}{$\begin{array}{r}\mu \\
(-)\end{array}$} \\
\hline C_a & 139.5 & 0.27 & $0.02 \%$ & $0.19 \% *$ & 9.9 \\
C_b & 170.5 & 0.33 & $0.05 \%$ & $0.34 \% *$ & 7.4 \\
C_c & 226.1 & 0.44 & $0.04 \%$ & $0.37 \% *$ & 9.5 \\
2FRCM_a & 448.2 & 0.88 & $0.42 \%$ & $2.23 \%$ & 5.4 \\
2FRCM_b & 493.5 & 0.97 & $0.34 \%$ & $1.13 \%$ & 3.3 \\
2FRCM_c & 411.4 & 0.81 & $0.22 \%$ & $1.11 \%$ & 5.0 \\
2FRM-A_a & 350.6 & 0.69 & $0.11 \%$ & $1.78 \%$ & 16.3 \\
2FRM-A_b & 294.8 & 0.58 & $0.05 \%$ & $1.40 \%$ & 26.0 \\
2FRM-A_c & 414.1 & 0.81 & $0.13 \%$ & $1.78 \%$ & 13.4 \\
2FRM-B_a & 368.5 & 0.72 & $0.15 \%$ & $0.85 \%$ & 5.8 \\
2FRM-B_b & 392.2 & 0.77 & $0.07 \%$ & $1.02 \%$ & 15.0 \\
2FRM-B_c & 273.9 & 0.54 & $0.06 \%$ & $1.41 \%$ & 25.7 \\
1FRCM_a & 260.3 & 0.51 & $0.58 \%$ & $1.58 \%$ & 2.7 \\
1FRCM_b & 326.7 & 0.64 & $0.46 \%$ & $1.38 \%$ & 3.0 \\
1FRCM_c & 280.7 & 0.55 & $0.33 \%$ & $1.46 \%$ & 4.4 \\
1FRM-A_a & 254.6 & 0.50 & $1.36 \%$ & $2.29 \%$ & 1.7 \\
1FRM-A_b & 277.3 & 0.54 & $0.43 \%$ & $3.83 \%$ & 9.0 \\
1FRM-A_c & 269.8 & 0.53 & $0.15 \%$ & $2.48 \%$ & 16.5 \\
1FRM-B_a & 403.6 & 0.79 & $0.09 \%$ & $0.87 \%$ & 9.4 \\
1FRM-B_b & 297.2 & 0.58 & $0.50 \%$ & $2.01 \%$ & 4.0 \\
1FRM-B_c & 256.4 & 0.50 & $0.08 \%$ & $1.07 \%$ & 13.0 \\
\hline
\end{tabular}

*End of the test, 20\% strength degradation not achieved of $20 \%$ of the peak force or as the strain at the end of the test, if the strength degradation was not achieved. The experimental results in terms of shear stress, $\tau$, shear strain, $\gamma$, and diagonal compression deformability, $\mu$, were collected in Table 3 .

\subsection{Specimens strengthened with FRCM}

The shear stress-strain experimental relationships for masonry panels strengthened with FRCM were plotted in Fig. 4. The response of single-side and double-side strengthening configurations were compared to each other and with control specimens. On the vertical axis, the shear stresses calculated according to ASTM E 519-07 provisions were reported.

The three control specimens achieved a brittle behaviour, with a sudden loss of capacity right after the peak. Conversely, specimens strengthened with FRCM had a ductile behaviour, with the achievement of large deformations before failure, both in singleside and double-side configurations. The failure mode was governed by the formation of multiple diagonal cracks in the matrix (Fig. 5). No tensile rupture of the grid or debonding/delamination mechanisms were detected for all the specimens. In the case of singleside strengthening, no significant out-of-plane displacements were observed despite the asymmetric configuration $[9,14]$.

\subsection{Specimens strengthened with FRM-type A}

The experimental performance of specimens strengthened with the FRM-A technique was depicted in

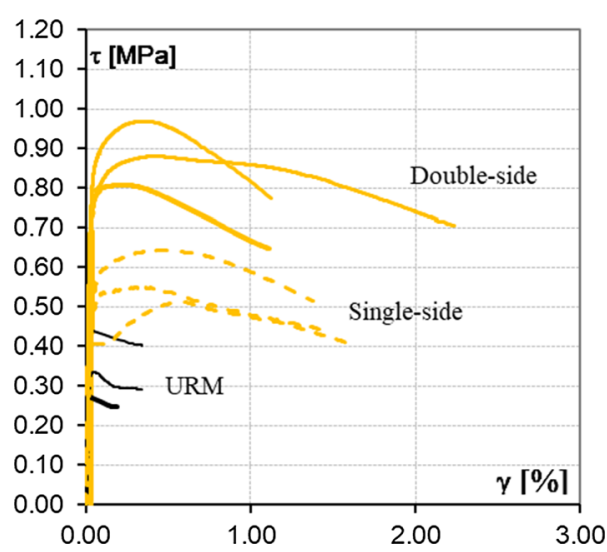

Fig. 4 FRCM strengthened panels: stress-strain curves 

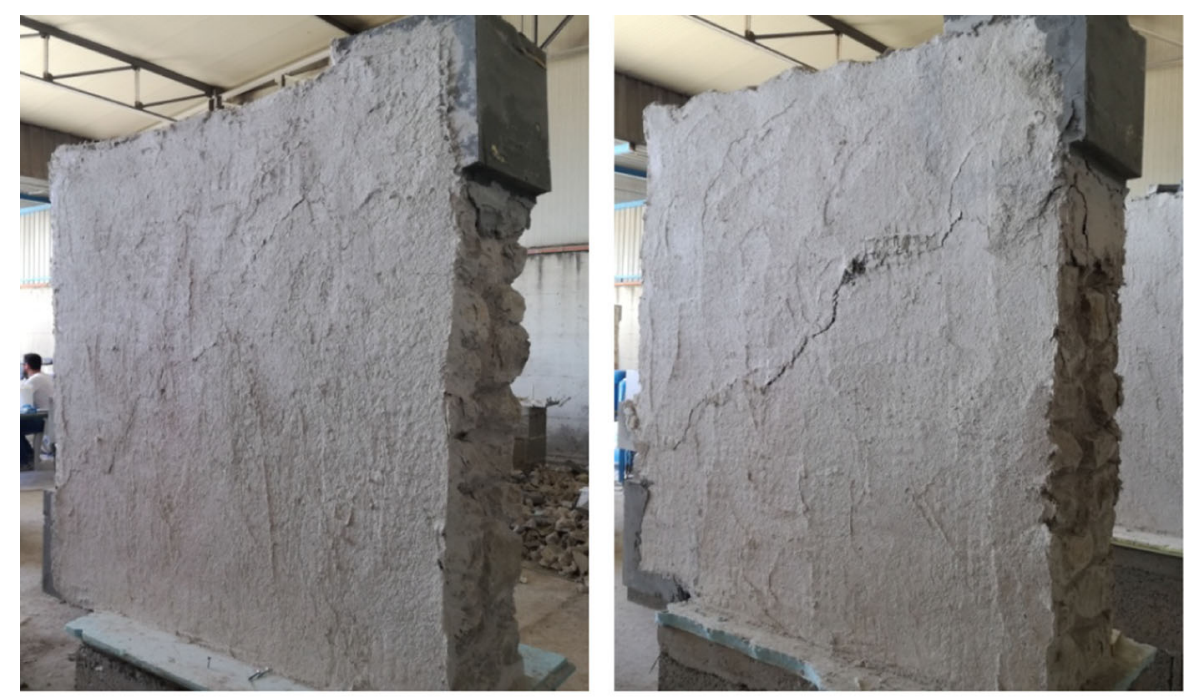

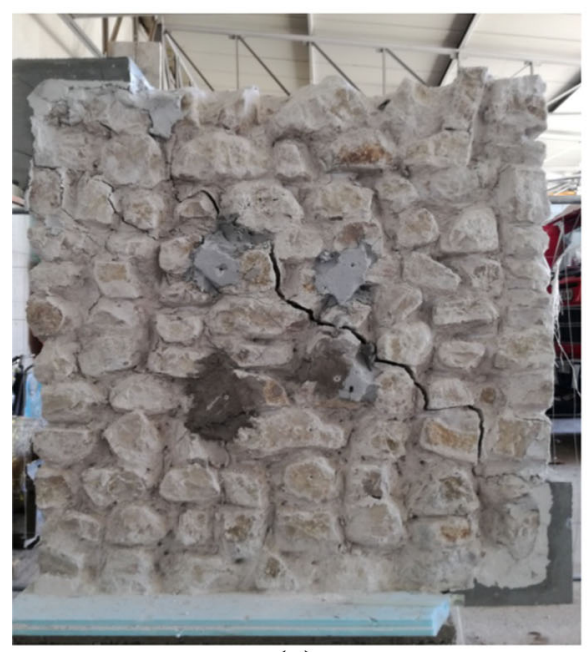

(a)

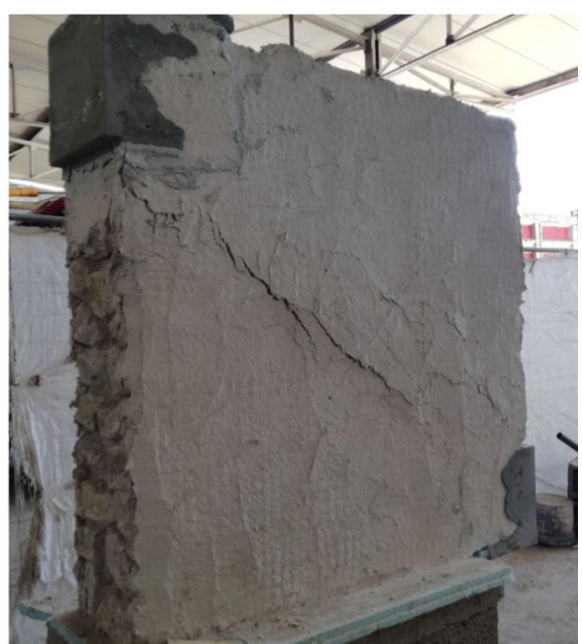

(b)

Fig. 5 FRCM strengthened panels: crack pattern at failure for a single-side configuration and b double-side configuration

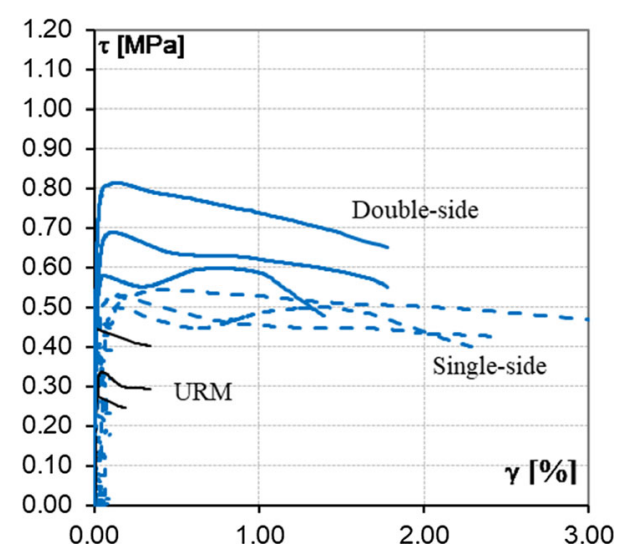

Fig. 6 FRM-A strengthened panels: stress-strain curves
Fig. 6. In this case, a large scatter in stress-strain curves was observed for specimens strengthened in double-side configuration with respect to the singleside one. Indeed, all the single-side strengthened specimens experienced a quite stable stress-strain response. The cracks pattern at failure generally appeared as a single diagonal macro-crack, see Fig. 7.

\subsection{Specimens strengthened with FRM-type B}

Figure 8 reported the experimental stress-strain curves derived for specimens strengthened with the FRM-B technique for single-side and double-side 

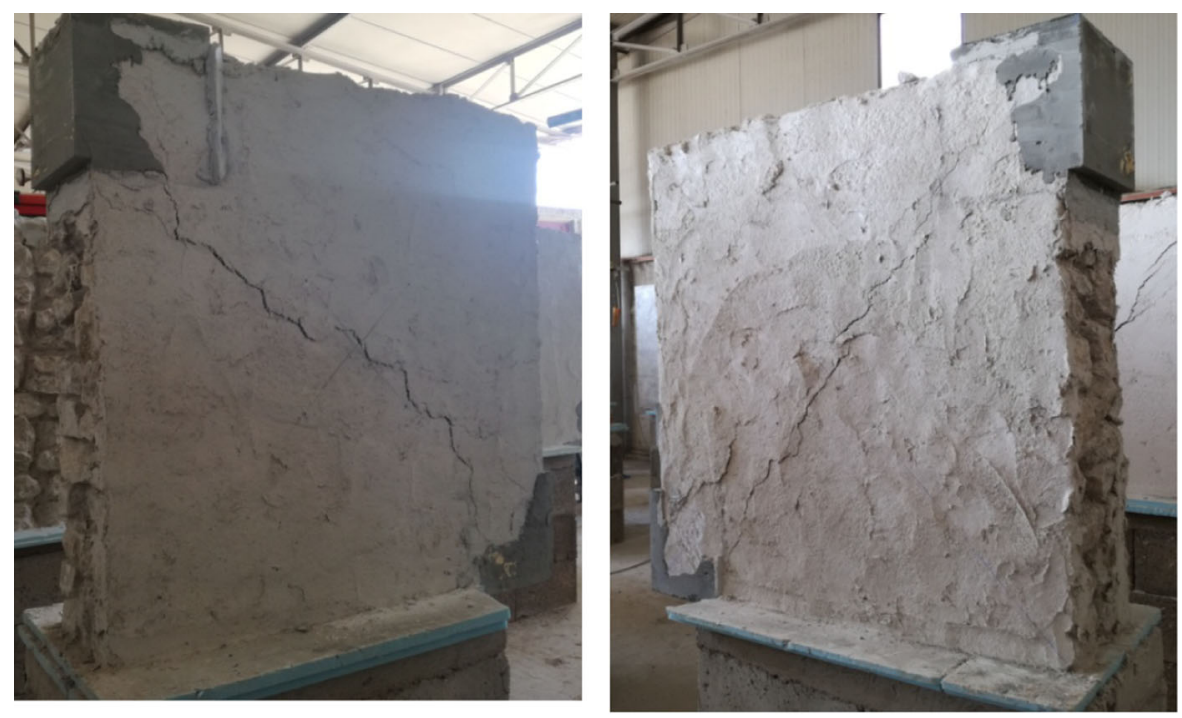

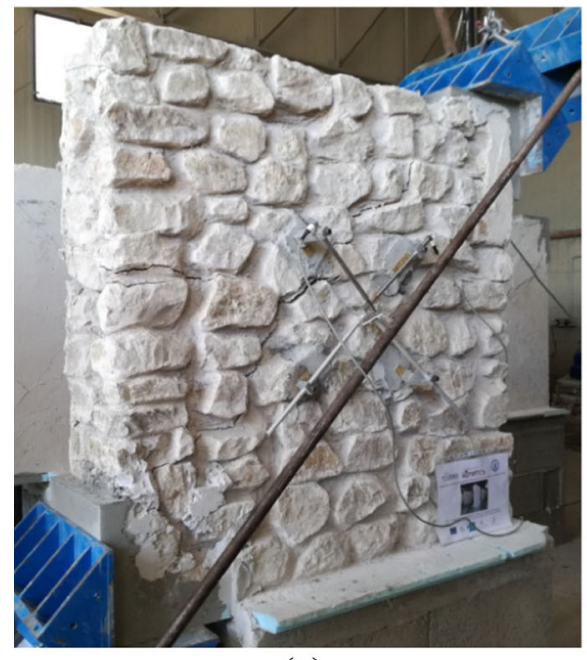

(a)

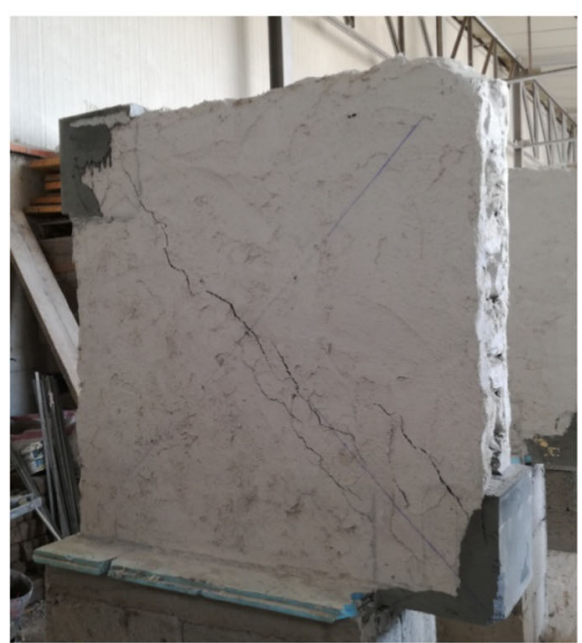

(b)

Fig. 7 FRM-A strengthened panels: crack pattern at failure for a single-side configuration and b double-side configuration

strengthening configurations. In this case, the stressstrain curves were less scattered, both for single-sided and double-sided configurations. At failure, the crack patterns were similar to those experienced by specimens strengthened with FRM-A, with the development of a single macro-crack (Fig. 9).

\section{Discussion of test results and analytical models}

In the following sections, the experimental results were discussed and compared to point out the role of the grid and of fibres content on the effectiveness of the strengthening techniques. Then, the experimental results were compared with those obtained in previous studies [5] on clay brick masonry panels with regular texture strengthened with same techniques. Finally, analytical models for predicting the shear contribution provided by the inorganic composites were investigated and mean strength amplification factors were derived.

\subsection{In-plane shear capacity}

Average values of peak shear stresses, strains at peak shear capacity and ultimate strains were summarized 


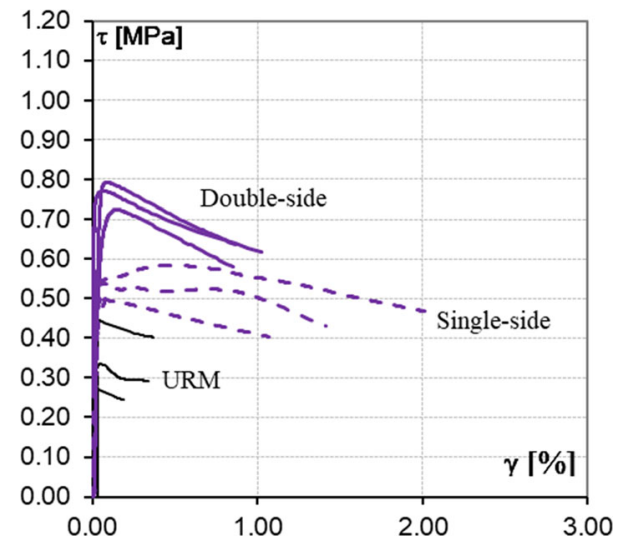

Fig. 8 FRM-B strengthened panels: stress-strain curves in Table 4, along with their $\mathrm{CoV}$, to further understand the performance of strengthened specimens with respect to the control ones. It was generally observed that the experimental results were quite scattered (i.e. large $\mathrm{CoV}$, especially in terms of $\gamma_{\max }$ ), probably due to the irregular texture of limestone blocks that led to different interlock resisting mechanisms. However, the adopted strengthening techniques provided a significant increase in shear capacity of masonry panels, which showed an average peak shear capacity of 0.35 MPa. Strengthened panels achieved average peak shear stresses ranging between 0.57 and $0.62 \mathrm{MPa}$ (i.e. $+63 \%$ and $+80 \%$, respectively) in single-side configuration and between 0.68 and
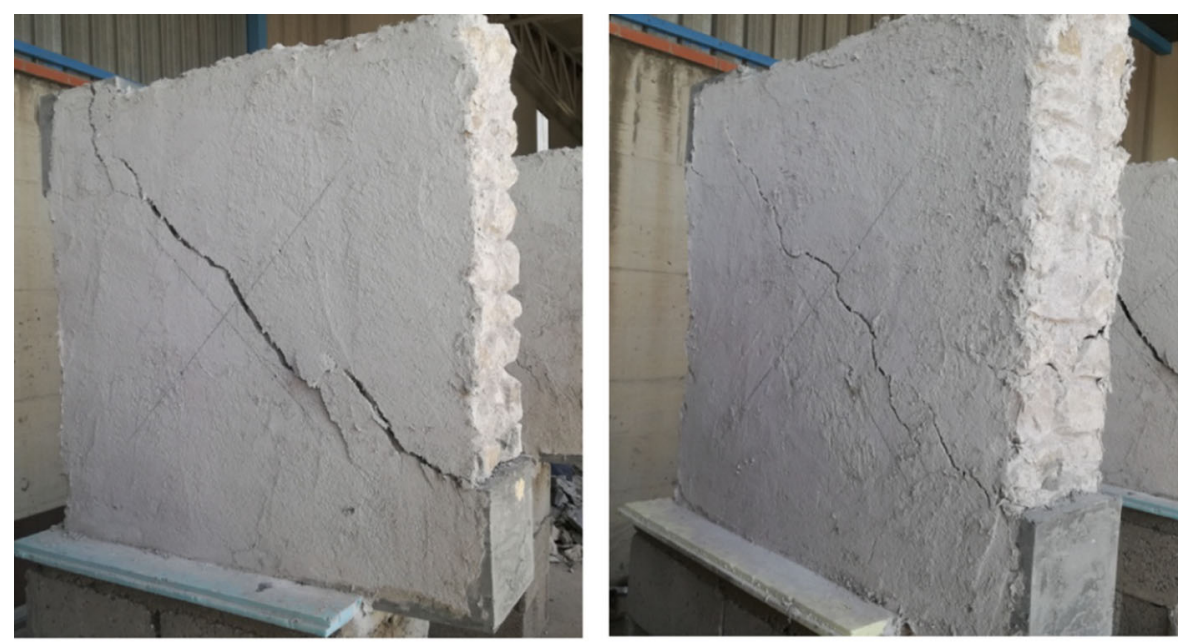

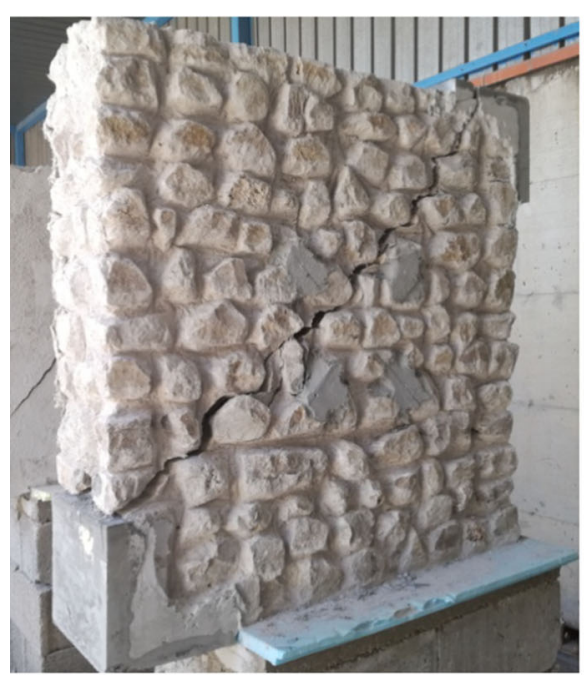

(a)

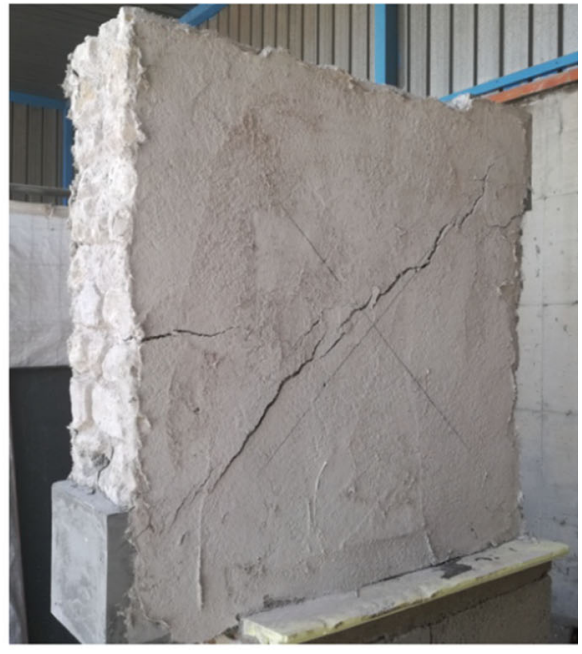

(b)

Fig. 9 FRM-B strengthened panels: crack pattern at failure for a single-side configuration and b double-side configuration 
Table 4 Average values (and $\mathrm{CoV}$ ) of peak shear stresses, strains at peak shear capacity and ultimate strains

\begin{tabular}{|c|c|c|c|c|c|c|c|c|c|c|c|c|}
\hline \multirow{3}{*}{$\begin{array}{l}\text { Strengthening technique } \\
\\
\text { Control }\end{array}$} & \multicolumn{6}{|c|}{ Single-side } & \multicolumn{6}{|c|}{ Double-side } \\
\hline & \multicolumn{2}{|c|}{$\begin{array}{l}\tau_{\text {ASTM,max }} \\
(\mathrm{MPa})\end{array}$} & \multicolumn{2}{|l|}{$\begin{array}{l}\gamma_{\tau \max } \\
(-)\end{array}$} & \multicolumn{2}{|l|}{$\begin{array}{l}\gamma_{u} \\
(-)\end{array}$} & \multicolumn{2}{|c|}{$\begin{array}{l}\tau_{\text {ASTM,max }} \\
(\mathrm{MPa})\end{array}$} & \multicolumn{2}{|l|}{$\begin{array}{l}\gamma_{\tau \max } \\
(-)\end{array}$} & \multicolumn{2}{|l|}{$\begin{array}{l}\gamma_{u} \\
(-)\end{array}$} \\
\hline & 0.35 & $(25 \%)$ & $0.04 \%$ & $(42 \%)$ & $0.3 \% *$ & $(32 \%)$ & 0.35 & $(25 \%)$ & $0.04 \%$ & $(42 \%)$ & $0.3 \% *$ & $(32 \%)$ \\
\hline FRCM & 0.57 & $(12 \%)$ & $0.46 \%$ & $(27 \%)$ & $1.5 \%$ & $(7 \%)$ & 0.89 & $(9 \%)$ & $0.33 \%$ & $(43 \%)$ & $1.5 \%$ & $(43 \%)$ \\
\hline FRM-A & 0.52 & $(4 \%)$ & $0.65 \%$ & $(98 \%)$ & $2.9 \%$ & $(29 \%)$ & 0.69 & $(17 \%)$ & $0.10 \%$ & $(43 \%)$ & $1.7 \%$ & $(13 \%)$ \\
\hline FRM-B & 0.62 & $(24 \%)$ & $0.22 \%$ & $(107 \%)$ & $1.3 \%$ & $(46 \%)$ & 0.68 & $(18 \%)$ & $0.09 \%$ & $(53 \%)$ & $1.1 \%$ & $(26 \%)$ \\
\hline
\end{tabular}

*End of the test, $20 \%$ strength degradation not achieved

$0.89 \mathrm{MPa}$ (i.e. $+95 \%$ and $+156 \%$, respectively) in double-side configuration.

\subsection{Comparison between FRCM and FRM-A}

To understand the effect of the grid on the overall behaviour of strengthened panels, the performance of specimens strengthened with the FRM-A technique was compared with that of specimens strengthened with FRCM. Note that the difference between the two strengthening techniques was only the absence of the grid, since the mortar was the same for both systems. To point out the role of the grid on the overall behaviour of strengthened specimens, the rate of increase of peak shear stress with respect to the average capacity of control specimens was plotted in Fig. 10a. The average rate of increase for each set of specimens was also reported in dashed line in Fig. 10a. It was observed that specimens strengthened with FRCM achieved a greater increase of peak shear capacity with respect to specimens strengthened with FRM-A. Indeed, average rates of increase of $156 \%$ and $100 \%$ were achieved respectively for FRCM and FRM-A panels in double-side configuration. The difference in rate of increase was less significant for panels in single-side configuration, with average rates of $63 \%$ and $51 \%$ for FRCM and FRM-A, respectively.

In terms of deformability, the experimental results were quite scattered for all the sets of specimens, with large CoVs (see Table 4). Looking at the ultimate deformation, the rate of increase with respect to the average deformation capacity of control specimens showed a negligible difference for specimens in double-side configuration for both FRCM and FRMA, see Fig. 10b. Conversely, specimens strengthened in single-side configuration with FRM-A experienced a greater deformation capacity with respect to specimens with FRCM.

Furthermore, from stress-stain relationships it was observed that FRCM strengthened specimens in double-side configuration achieved the peak shear capacity for significantly larger strains with respect to control specimens (i.e. $0.33 \%$ for FRCM and $0.04 \%$ for control specimens, on average). Furthermore, a clear non-linear behaviour was visible before the achievement of peak strength (see Fig. 4). Conversely, specimens strengthened with FRM-A technique experienced the peak capacity for shear deformations lower (i.e. $0.10 \%$ ) than that achieved by FRCM panels, and an almost elastic behavior before the achievement of peak capacity (see Fig. 6). This is an important aspect for evaluating the performance of strengthened specimens, since the peak shear capacity is usually associated with the development of first significant cracks in the matrix. Thus, the presence of the grid delayed the development of cracks in the matrix, allowing the achievement of higher shear deformations at the peak capacity. Furthermore, it was noted that specimens in single-side configuration achieved the peak shear capacity at higher deformations with respect to the double-side configuration, both for FRCM and FRM-A. This was probably related to the reduced stiffness of the panels with asymmetrical external reinforcement after the development of first micro-cracks in the masonry panel.

The grid also affected the failure mode, leading to the occurrence of a multi-cracking pattern instead of a single macro-crack developed when the FRM-A technique is adopted. 


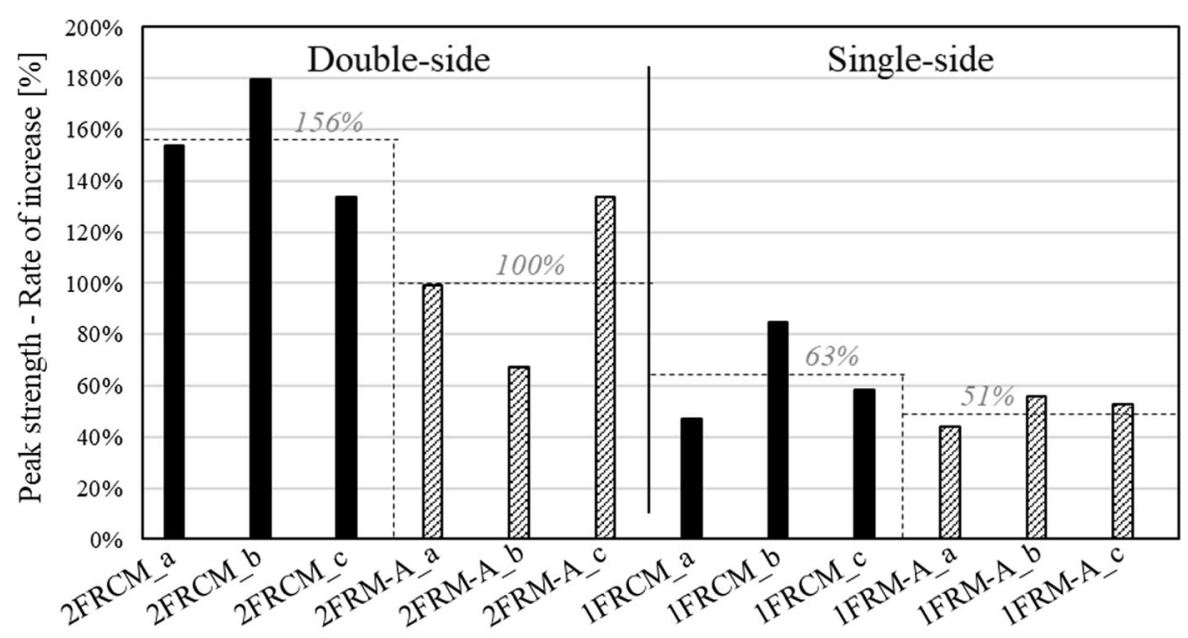

(a)

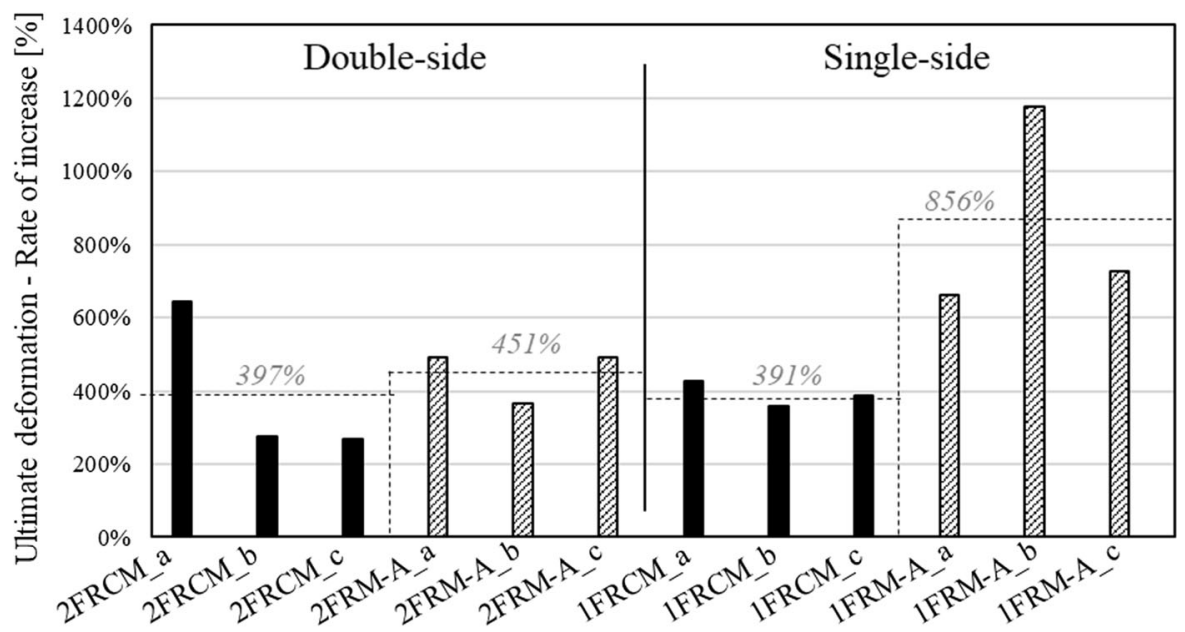

(b)

Fig. 10 Role of the grid on the rate of increase of peak shear stresses (a) and ultimate deformation (b): FRCM versus FRM-A

\subsection{Comparison between FRM-A and FRM-B}

To investigate the effect of different fibre contents on the effectiveness of the FRM strengthening technique, the performances of specimens strengthened with FRM-A and FRM-B techniques were herein compared (i.e. fibre content difference $<50 \%$ ). The rate of increase of peak shear stress with respect to the average capacity of control specimens was plotted in Fig. 11a for specimens strengthened with FRM-A and with FRM-B, respectively.

The comparison showed that the different fibre content of the two composites (less than $50 \%$ in weight, with overall content less than $0.8 \%$ in weight) slightly affected the peak shear capacity of the specimens in double-side configuration (i.e. rate of increase of $100 \%$ for FRM-A and 95\% for FRM-B). The effect of different fibre content was more visible for panels in single-side strengthening configuration, where FRM-B specimens experienced an average rate of increase of $80 \%$ with respect to the average rate of $51 \%$ achieved by FRM-A specimens.

The rate of increase of ultimate deformations was depicted in Fig. 11b. In double-side configuration, the difference in average ultimate deformation capacity between FRM-A and FRM-B was negligible. Conversely, in single-side configuration, FRM-B 


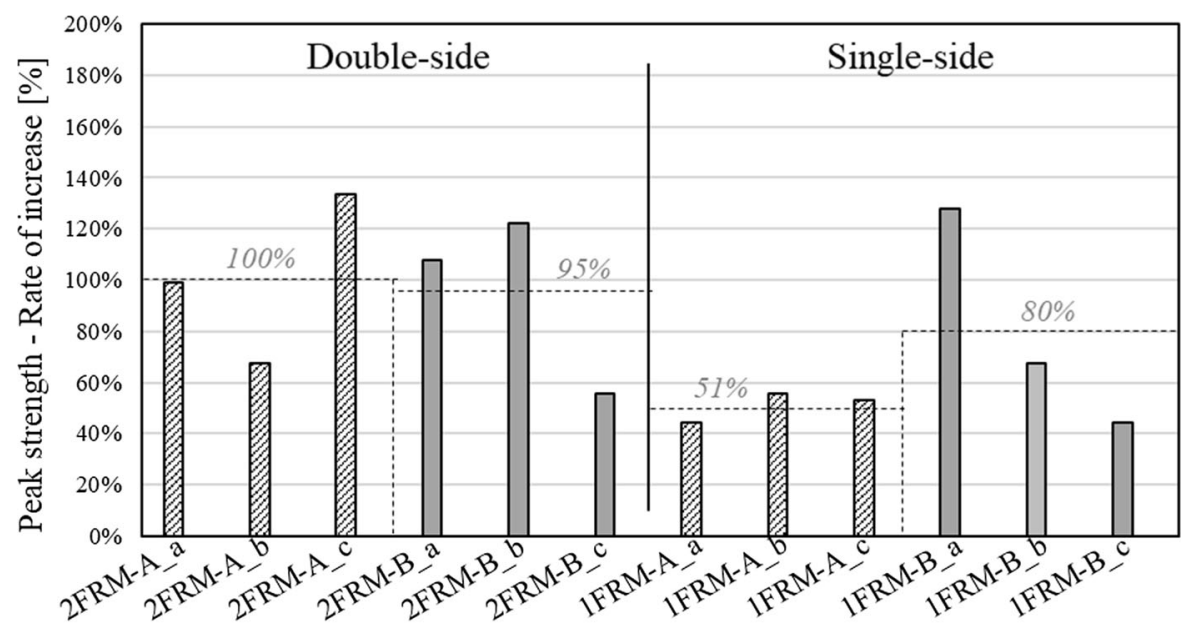

(a)

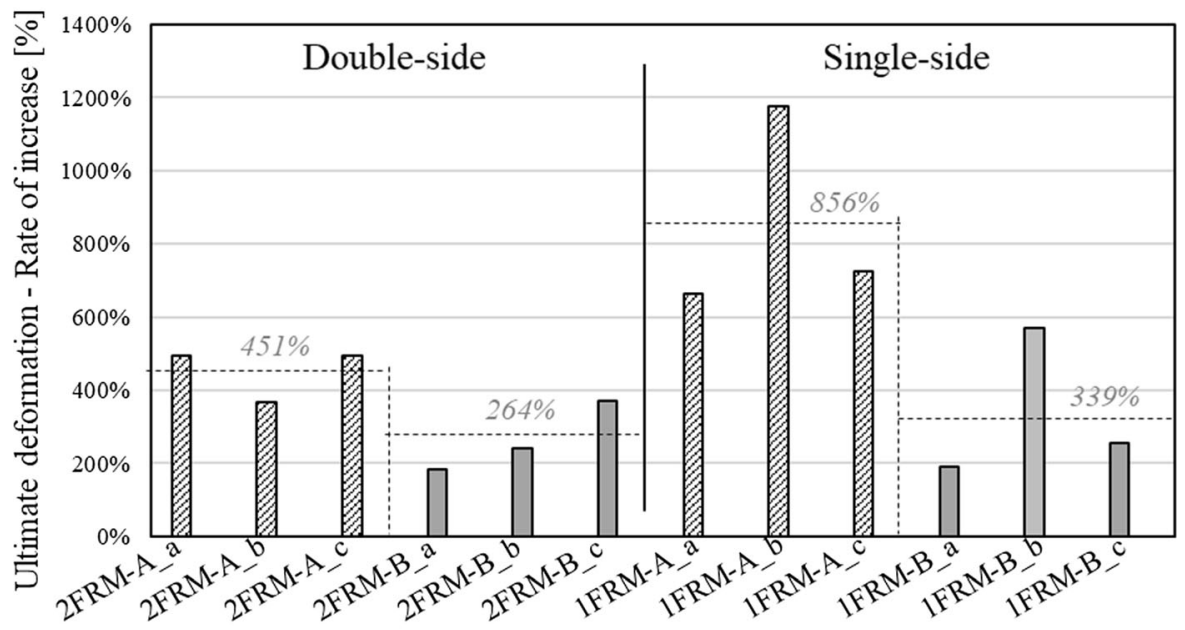

(b)

Fig. 11 Role of the fibres content on the rate of increase of peak shear stresses (a) and ultimate deformation (b): FRM-A versus FRM-B

specimens experienced a slightly greater deformation capacity with respect to FRM-A.

In terms of deformability at peak shear capacity, FRM-A and FRM-B panels in double-side configuration achieved the peak shear stress at very similar shear deformations (i.e. $0.10 \%$ and $0.09 \%$, respectively). In single-side configuration, the large scatter of results did not allow to define a general response.

A difference in fibre content less than $50 \%$ over an overall fibre content ratio $<1 \%$ in weight did not affect the failure mode, governed by the formation of a large macro-crack both for FRM-A and FRM-B techniques.

\subsection{Effect of masonry texture}

The experimental response of strengthened limestone masonry panels with irregular texture was compared with that of clay brick panels strengthened with same techniques [5]. Two-leaf clay brick masonry panels (thickness $285 \mathrm{~mm}$ ) were strengthened in double-side configuration with FRCM and FRM-B techniques and were tested under diagonal compression. The FRCM adopted for clay brick was made with the same mortar used for the limestone masonry panels with irregular texture herein presented. However, in the case of clay brick panels, a basalt FRP grid (BFRP, spacing $6 \times 6$ $\mathrm{mm}$, equivalent thickness 0.039 , Elastic modulus 70 
GPa) was used instead of the GFRP grid (spacing $25 \times 25 \mathrm{~mm}$, equivalent thickness 0.035 , Elastic modulus $89 \mathrm{GPa}$ ) one adopted for limestone masonry panels. Hence, in the case of FRCM, the comparison between the two masonry textures is more qualitative than quantitative.

To point out the effectiveness of double-side FRCM and FRM-B strengthening techniques on masonry panels with regular and irregular texture, the rate of increase of peak shear stress with respect to the average capacity of URM panels was compared and showed in Fig. 12 for clay brick regular texture and limestone irregular texture masonry panels. The comparison between the two sets of specimens (i.e. clay brick and limestone) showed that FRCM technique was more effective in enhancing the shear capacity of limestone masonry with respect to the clay brick one (i.e. average rate of increase of $156 \%$ for limestone with GRFP and of $64 \%$ for clay brick masonry with BFRP). The strong difference can be also related to the different grid adopted for FRCM in the two sets of specimens, especially in terms of mesh size and axial stiffness. Same result was observed for FRM-B technique, even though with a reduced difference between the two sets of specimens (i.e. average rate of increase of $95 \%$ for limestone vs. $77 \%$ for clay brick masonry).

It should be observed that, even though the scatter of results, clay brick panels strengthened with FRM-B achieved a slightly higher average rate of increase of shear capacity with respect to same specimens strengthened with FRCM. Conversely, limestone masonry panels experienced an opposite behaviour, with a higher rate of increase with the FRCM technique rather than with FRM-B. Thus, based on these results, the role of the grid was more relevant in the case of limestone masonry panel with irregular texture rather than in clay brick masonry panels with a regular texture, providing a substantial enhancement of the in-plane shear capacity.

\subsection{Analytical models for FRCM}

The American code ACI 549.4-R13 [19] and the Italian Guidelines CNR-DT 215 [18] provided analytical models for calculating the shear capacity of FRCM strengthened masonry walls, computed with an additive approach as the sum of the shear capacity of URM walls and the shear contribution due to the FRCM system, $V_{f}$. According to the ACI 549.4-R13, $V_{f}$ can be calculated as:

$V_{f, A C I}=2 n A_{f} L E_{f} \varepsilon_{f}$

where $A_{f}$ is the area of embedded mesh reinforcement by unit width, $n$ is the number of layers of mesh reinforcement, $L$ is the wall width in the direction of applied shear force, $E_{f}$ is the tensile modulus of elasticity of the cracked FRCM composite material and $\varepsilon_{f}$ is the ultimate tensile strain of FRCM shear reinforcement. According to the ACI 549.4-R13, the FRCM tensile strain should be limited to 0.004 for design purpose. Based on experimental evidences [26], the elastic modulus of cracked FRCM can be assumed equal to that of the mesh reinforcement.

Conversely, according to the CNR-DT 215, $V_{f}$ can be calculated as:

$V_{f, \mathrm{CNR}}=n t_{f} L \alpha E_{f} \varepsilon_{f, \lim } / \gamma_{m}$

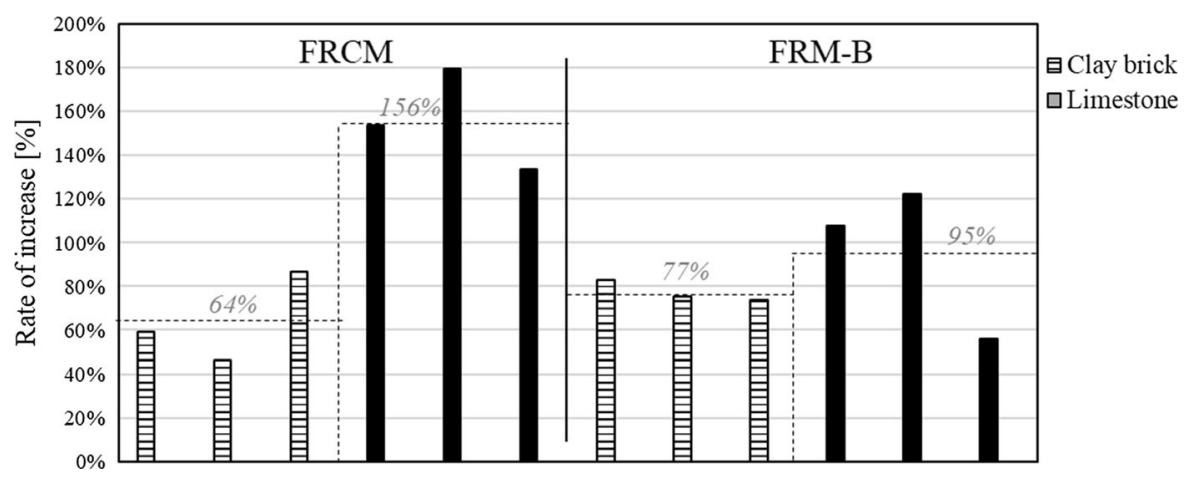

Fig. 12 Rate of increase of peak shear stresses for FRCM and FRM-B strengthening techniques on clay brick and limestone masonry panels 
where $t_{f}$ is the equivalent thickness of the mesh reinforcement, $\alpha$ is a reduction factor that account for the fibres biaxial state of stress (to be assumed equal to $0.8), \varepsilon_{f, \text { lim }}$ is the limit strain for delamination and $\gamma_{m}$ is a model coefficient, equal to 2 according to CNR-DT 215.

The two analytical models were adopted for predicting the shear contribution of FRCM for limestone masonry panels with irregular texture, by adopting the mechanical properties derived from experimental tests and the code's prescriptions. Note that for the application of the CNR-DT 215 model, the knowledge of the limit strain for delamination, $\varepsilon_{f \text {,lim }}$, is required. In the absence of delamination tests for the FRCM system herein adopted, the ultimate stain of the grid derived from tensile tests was used for calculations.

The results of analytical predictions for FRCM system according to Eqs. 3-4 were reported in Table 5 along with the comparison with experimental values. The experimental shear contribution of FRCM system was calculated by subtracting the experimental average peak force recorded for control specimens, $V_{\text {control}}$, to the shear force sustained by strengthened specimens, $V_{\text {tot }}$ (i.e. $\left.V_{f \text { exp }}=V_{\text {tot }}-V_{\text {control }}\right)$.

Both analytical models for FRCM strongly underestimated the experimental capacity of strengthening systems, with error ranging between -69 and $-82 \%$. In the case of $V_{f, \mathrm{ACI}}$, the safe predictions were related to the design limitation of fibres stain $\varepsilon_{f}$ to 0.004 . To achieve the average experimental shear capacity by means of the ACI 549.4 approach in Eq. 3, the fibres strain $\varepsilon_{\text {fexp,ACI }}$ should be assumed equal to the ultimate strain of the grid, $1.4 \%$ (i.e. mean value from experimental tests), for the double-side configuration and to $1.3 \%$ for the single-side configuration, as reported in Table 5.

Table 5 Analytical predictions for FRCM shear contribution

\begin{tabular}{lllllll}
\hline & $\begin{array}{l}V_{f, \exp } \\
(\mathrm{kN})\end{array}$ & $\begin{array}{l}V_{f, \mathrm{ACI}} \\
(\mathrm{kN})\end{array}$ & $\begin{array}{l}\text { Error } \\
(\%)\end{array}$ & $\begin{array}{l}\varepsilon_{f, \exp , \mathrm{ACI}} \\
(-)\end{array}$ & $\begin{array}{l}V_{f, \mathrm{CNR}} \\
(\mathrm{kN})\end{array}$ & $\begin{array}{l}\text { Error } \\
(\%)\end{array}$ \\
\hline $\begin{array}{c}\text { Double- } \\
\text { side }\end{array}$ & 192 & 48 & -75 & 0.014 & 34 & -82 \\
\begin{tabular}{l} 
Single-side \\
\hline
\end{tabular} & 78 & 24 & -69 & 0.013 & 17 & -78 \\
\hline
\end{tabular}

4.6 Proposed analytical model for FRM

In the case of FRM strengthening systems, a lack of analytical models and of international standards for such applications was recognized. Thus, an analytical formulation based on Eq. 5 was adopted for estimating the in-plane shear contribution of the FRM strengthening system, as follows:

$V_{f, \mathrm{FRM}}=n t L \sigma_{t} / \gamma_{m}$

where $n$ is the number of sides where the reinforcement is applied, $t$ is the thickness of the fibre reinforced mortar and $\sigma_{t}$ is the tensile strength of the fibre reinforced mortar. The model coefficient, $\gamma_{m}$, is assumed equal to 2, as for the case of FRCM system in Eq. 4.

The analytical model in Eq. 5 was adopted for predicting the in-plane shear contribution of FRM systems and the results were summarised in Table 6 along with the experimental shear contribution of FRM systems. The tensile strengths of the fibre reinforced mortars used for the theoretical prediction were the experimental mean values reported in Table 1. The comparison between analytical and average experimental FRM shear contributions showed a good accuracy of Eq. 5 for predicting the capacity of FRM systems, with errors ranging between -4 and $-24 \%$.

\subsection{Shear strength amplification factors}

As an alternative to the analytical approach, the CNRDT 215 provides also a simplified method consisting in mean shear strength amplification factors for different masonry typologies to be adopted for accounting for the effect of traditional strengthening solutions. For instance, according to the CNR-DT 215, the original shear strength of masonry with irregular

Table 6 Analytical predictions for FRM shear contribution

\begin{tabular}{llrcr}
\hline & & $\begin{array}{l}V_{f, \exp } \\
(\mathrm{kN})\end{array}$ & $\begin{array}{l}V_{f, \mathrm{FRM}} \\
) \mathrm{kN})\end{array}$ & $\begin{array}{l}\text { Error } \\
(\%)\end{array}$ \\
\hline Double-side & FRM-A & 123 & 119 & -4 \\
& FRM-B & 117 & 108 & -8 \\
Single-side & FRM-A & 63 & 59 & -5 \\
& FRM-B & 99 & 76 & -24 \\
\hline
\end{tabular}


Table 7 Shear stress amplification factors

\begin{tabular}{|c|c|c|c|c|c|}
\hline & \multicolumn{5}{|l|}{$\tau_{\max } / \tau_{0}$} \\
\hline & 1FRCM & 2FRCM & $2 \mathrm{FRCM}+$ anchors & 1FRM & 2FRM \\
\hline \multicolumn{6}{|c|}{ Soft rocks-uncoursed } \\
\hline$n$. tests & 3 & 3 & $11 *$ & 6 & 6 \\
\hline Mean & 1.6 & 2.6 & $3.6^{*}$ & 1.7 & 2.0 \\
\hline SD & 0.19 & 0.23 & $0.90 *$ & 0.31 & 0.30 \\
\hline $\mathrm{CoV}$ & $12 \%$ & $9 \%$ & $30 \% *$ & $19 \%$ & $15 \%$ \\
\hline $16^{\circ}$ perc. & 1.4 & 2.3 & $2.7 *$ & 1.3 & 1.7 \\
\hline
\end{tabular}

*From Del Zoppo et al. [9]

texture can be amplified up to 1.5 times in the case of strengthening with FRCM.

Shear stress amplification factors have been derived for different masonry typologies on an enlarged database of 414 experimental tests in Del Zoppo et al. [9]. In this study, only tests on masonry panels with irregular texture reinforced with FRCM in double-side configuration and anchors were found in literature and were collected to derive amplification factors. To define amplification factors for this class of masonry panels with other strengthening configurations (i.e. single or double-side FRCM or also FRM), the amplification factors were defined as the ratio between the peak shear stress of the strengthened panel and the average peak shear stress of control specimens, $\tau_{\max } / \tau_{0}$. The meaningful statistics for the distribution of $\tau_{\max } / \tau_{0}$ were calculated and summarized as reported in Table 7 for each strengthening technique and configuration (i.e. $1 \mathrm{FRCM}=$ singleside FRCM, 2FRCM = double-side FRCM, 1FRM = single-side $\quad$ FRM,$\quad$ 2FRM = double-side FRM). Mean and standard deviations were reported, along with the $\mathrm{CoV}$ and the $16^{\text {th }}$ percentile of the $\tau_{\max }$ l $\tau_{0}$ distribution. The results found in [9] for the 2FRCM with anchors strengthening solution were also reported for the sake of completeness (grey colour text).

\section{Conclusions}

An experimental program on 21 limestone rubble blocks masonry panels with irregular texture under diagonal compression was carried out to investigate the in-plane shear capacity of such masonry typology strengthened with inorganic composites. Two classes of composites, FRCM and FRM, were adopted in this study, and different fibres content ratios for the FRM were investigated (i.e. difference $<50 \%$ in weight).
The role of grid was analysed from the comparison between FRCM and FRM. Furthermore, the influence of fibre contented in FRM was also pointed out. The influence of symmetrical and asymmetrical external reinforcement (i.e. single-side and double-side configurations) on the diagonal compression capacity was also investigated. The experimental results obtained for masonry panels with irregular texture were compared with those achieved for clay brick masonry panels strengthened with same techniques. Finally, analytical predictions of the experimental outcomes were reported, and an analytical model was proposed for estimating the shear contribution of FRM systems. Furthermore, shear stress mean amplification for each strengthening technique and configuration were derived.

The main results are summarized as follows:

- All the adopted strengthening techniques (FRCM and FRM in single or double-side configuration) provided a significant enhancement of the in-plane shear capacity of limestone masonry panels with irregular texture, with average peak shear stresses increase ranging between +63 and $+80 \%$, for single-side configuration and between +95 and $+156 \%$, for double-side configuration;

- The comparison between specimens strengthened with FRCM and FRM-A techniques showed that the grid played an important role for the peak capacity of panels. In terms of strength, specimens strengthened with FRCM achieved a greater increase of peak shear capacity with respect to specimens strengthened with FRM-A, with average rates of increase of $156 \%$ and $100 \%$ for FRCM and FRM-A panels in double-side configuration, respectively. This difference was less significant for panels in single-side configuration, with average rates of $63 \%$ and $51 \%$ for FRCM and FRM-A, 
respectively. In terms of deformability, specimens strengthened with FRCM showed a clear nonlinear behavior and achieved the peak capacity for larger shear deformations with respect to panels strengthened with FRM-A, that experienced a quasi-elastic behavior before the achievement of peak strength;

- The comparison between specimens strengthened with FRM-A and FRM-B techniques pointed out that a difference lower than $50 \%$ in fibres content ratio embedded in the matrix slightly affected the overall performance of strengthened specimens;

- From the comparison between limestone masonry panels with irregular texture and clay brick panels strengthened with FRCM and FRM-B techniques, it was observed that both strengthening techniques were more effective in the case of limestone panels than clay brick ones for enhancing the diagonal compression capacity. Furthermore, the effect of the grid on the overall capacity was more evident in the case of limestone masonry panels. Indeed, clay brick panels strengthened with FRCM and FRM-B techniques experienced very similar rates of increase of peak shear stresses;

- Analytical model provided by CNR-DT 215 and ACI 549.4-R13 provided safe estimations of the experimental shear contribution of the FRCM, with errors ranging between -69 and $-78 \%$. To predict the FRCM experimental contribution, effective strains equal to the ultimate strain of the grid or slightly lower (1.3-1.4\%) were adopted in the ACI 549.4-R13 for double-side and single-side configurations, respectively;

- The analytical predictions derived with the analytical model proposed for estimating the FRM shear contribution were in good agreement with the experimental results, with error ranging between -4 and $-24 \%$.

- Based on the experimental results, masonry shear strength mean amplification factors were proposed for such masonry typology with different strengthening techniques adopting inorganic composites; they resulted in every case greater than 1.5 , value suggested by the CNR-DT 215 .

Acknowledgements Open access funding provided by Università degli Studi di Napoli Federico II within the CRUICARE Agreement. This study was performed in the framework of PE 2019-2021 joint program DPC Reluis. The materials used for the strengthening of specimens were provided by Mapei SpA, Milan.

\section{Compliance with ethical standards}

Conflict of interest The authors declare that they have no conflict of interest.

Open Access This article is licensed under a Creative Commons Attribution 4.0 International License, which permits use, sharing, adaptation, distribution and reproduction in any medium or format, as long as you give appropriate credit to the original author(s) and the source, provide a link to the Creative Commons licence, and indicate if changes were made. The images or other third party material in this article are included in the article's Creative Commons licence, unless indicated otherwise in a credit line to the material. If material is not included in the article's Creative Commons licence and your intended use is not permitted by statutory regulation or exceeds the permitted use, you will need to obtain permission directly from the copyright holder. To view a copy of this licence, visit http://creativecommons.org/licenses/by/4.0/.

\section{References}

1. Calderoni B, Cordasco EA, Del Zoppo M, Prota A (2020) Damage assessment of modern masonry buildings after the L'Aquila earthquake. Bull Earthq Eng 18:2275-2301 (2020). https://doi.org/10.1007/s10518-020-00784-5

2. Corradi M, Borri A (2018) A database of the structural behavior of masonry in shear. Bull Earthq Eng 16(9):3905-3930

3. Boschi S, Galano L, Vignoli A (2019) Mechanical characterisation of Tuscany masonry typologies by in situ tests. Bull Earthq Eng 17(1):413-438

4. Del Zoppo M, Di Ludovico M, Balsamo A, Prota A (2019) In-plane shear capacity of tuff masonry walls with traditional and innovative Composite Reinforced Mortars (CRM). Constr Build Mater 210:289-300

5. Del Zoppo M, Di Ludovico M, Balsamo A, Prota A (2019) Experimental in-plane shear capacity of clay brick masonry panels strengthened with FRCM and FRM composites. J Compos Constr 23(5):04019038

6. Consiglio Superiore dei Lavori Pubblici (2018) Linea Guida per la identificazione, la qualificazione ed il controllo di accettazione di compositi fibrorinforzati a matrice inorganica (FRCM) da utilizzarsi per il consolidamento strutturale di costruzioni esistenti. (in Italian)

7. D'Antino T, Carozzi FG, Poggi C (2019) Diagonal shear behavior of historic walls strengthened with composite reinforced mortar (CRM). Mater Struct 52(6):114

8. Calabrese AS, D’Antino T, Poggi C, Colombi P, Fava G, Pisani MA (2020) Application of externally bonded inorganic-matrix composites to existing masonry structures. In: Della Torre S, Bocciarelli M, Daglio L, Neri R (eds) Buildings for education. Springer, Cham, pp 283-292

9. Del Zoppo M, Di Ludovico M, Prota A (2019) Analysis of FRCM and CRM parameters for the in-plane shear 
strengthening of different URM types. Compos B Eng 171:20-33

10. Balsamo A, Iovinella I, Morandini G (2014) FRG strengthening systems for masonry building. In: Proceedings of NZSEE conference

11. Corradi M, Borri A, Castori G, Sisti R (2014) Shear strengthening of wall panels through jacketing with cement mortar reinforced by GFRP grids. Compos B Eng 64:33-42

12. Gattesco N, Boem I (2015) Experimental and analytical study to evaluate the effectiveness of an in-plane reinforcement for masonry walls using GFRP meshes. Constr Build Mater 88:94-104

13. Del Zoppo M, Maddaloni G, Di Ludovico M, Balsamo A, Prota A (2019) FRCM for the in-plane shear strengthening of masonry panels with irregular texture. In: Proceedings of ANIDIS 2019-XVIII conference. pp 18-25

14. Yardim Y, Lalaj O (2016) Shear strengthening of unreinforced masonry wall with different fiber reinforced mortar jacketing. Constr Build Mater 102:149-154

15. Oskouei AV, Jafari A, Bazli M, Ghahri R (2018) Effect of different retrofitting techniques on in-plane behavior of masonry wallettes. Constr Build Mater 169:578-590

16. Shabdin M, Zargaran M, Attari NK (2018) Experimental diagonal tension (shear) test of un-reinforced masonry (URM) walls strengthened with textile reinforced mortar (TRM). Constr Build Mater 164:704-715

17. Mantegazza G, Gatti A, Barbieri A (2006) Retrofitting concrete and masonry building: FRCM (fiber reinforced cementitious matrix) a new emerging technology. XII Konferencja Naukowo-Techniczna Problemy Remontowe W Budownictwie Ogólnym i Obiektach Zabytkowych REMO. pp 6-8

18. Research National Council (CNR). CNR-DT 215 (2018) Istruzioni per la Progettazione, l'Esecuzione ed il Controllo di Interventi di Consolidamento Statico mediante l'utilizzo di Compositi Fibrorinforzati a matrice inorganica (in Italian). Technical Document No. 215/2018

19. ACI 549.4 R-13 (2013) Guide to design and construction of externally bonded FRCM systems for repair and strengthening concrete and masonry structures. American Concrete Institute, Farmington Hills

20. EN 1996-1-1 (2005) Eurocode 6: design of masonry structures-part 1-1: general rules for reinforced and unreinforced masonry structures. Comité Européen de Normalisation, Brussels

21. Italian Building Code (2008) D.M. 14.01.2008: Norme Tecniche per le Costruzioni. Italian Ministry of Infrastructures and, Transportation [in Italian], Rome

22. UNI, EN 772-1 (2011) Methods of test for masonry units. Determination of compressive strength. Ente Nazionale Italiano di Unificazione, European Committee for Standardization

23. UNI EN 1015-11 (2001) Methods of test for mortar for masonry determination of flexural and compressive strength of hardened mortar

24. EN ISO 10618/2005 (2005) Carbon fiber-determination of tensile properties of resin impregnated yarn. UNI Standard

25. ASTM E 519-07 (2007) Standard test method for diagonal tension (shear) in masonry assemblages. American Society for Testing and Materials

26. Menna C, Balsamo A, Maddaloni G, Prota A (2018) Comparative assessment of the tensile behavior of steel and textile reinforced mortar systems. Spec Publ 324:1-2

Publisher's Note Springer Nature remains neutral with regard to jurisdictional claims in published maps and institutional affiliations. 